\title{
The Thiomethyl Anion: Formation, Reactivity, and Thermodynamic Properties
}

\author{
Steven R. Kass, Hangzhou Guo,* and Gregg D. Dahlke \\ Department of Chemistry, University of Minnesota, Minneapolis, Minnesota, USA
}

The thiomethyl anion (1) has been generated by fluorodesilylation of trimethylsilylmethanethiol in a variable-temperature flowing afterglow device. The proton affinity $\left(1649 \pm 12 \mathrm{~kJ} \mathrm{~mol}^{-1}\right)$ and electron affinity $(0.67 \pm .13 \mathrm{eV})$ were determined and compared to a previously reported molecular orbital calculation. Isomerization via a 1,2-proton shift does not take place between $-40^{\circ}$ and $100^{\circ} \mathrm{C}$ despite a $156 \mathrm{~kJ} \mathrm{~mol}^{-1}$ driving force. Ionmolecule reactions of 1 were examined with a number of reagents including $\mathrm{N}_{2} \mathrm{O}, \mathrm{O}_{2}, \mathrm{CS}_{2}$, $\mathrm{COS}$, and $\mathrm{CO}_{2}$. Hydride ion transfer was observed in every case, along with other products, and thermodynamic information has been derived. (J Am Soc Mass Spectrom 1990, 1, 366-371)

A nions that are thermodynamically labile can isomerize to more stable ions, at least in principle, via unimolecular rearrangements. Many examples of this type of ion have been reported in recent years, including several in which a 1,2-proton shift would lead to significant stabilization [1]. For instance, deprotonation of trimethylsilane produces an $\alpha$-silyl carbanion, which does not isomerize to the corresponding silyl anion (eq 1) despite a $\sim 42 \mathrm{~kJ} \mathrm{~mol}^{-1}$ driving force [1a]. Observations such as this indicate that there is a significant barrier for 1,2-proton shifts.

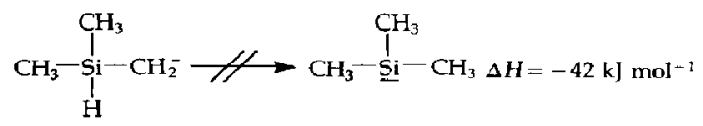

They are also in accord with the general structural integrity of anions and the fact that this particular process is forbidden by orbital symmetry considerations [2]. Nonetheless, the formation of thermodynamically labile ions such as the $\alpha$-silyl carbanion is often difficult, and only a few have been thoroughly examined.

It is well known that second-row elements such as silicon, phosphorous, and sulfur can stabilize a carbanion when they are adjacent to the charge $[1 a, 3]$. As a result, dimelhylsulfide $\left(\left(\mathrm{CH}_{3}\right)_{2} \mathrm{~S}\right)$ is readily deprotonated by a number of different bases and is approximately $98 \mathrm{~kJ} \mathrm{~mol}^{-1}$ more acidic than methane [3c]. Given the stability of the $\alpha$-thiocarbanion and its ease of formation, one might infer that the thiomethyl anion (1) would also be a viable species. Indeed, during the preparation of this manuscript Downard et al. [4] reported the existence of 1 in a double-sector mass spectrometer, and predicted some of its characteristics with the aid of $a b$ initio molecular orbital calculations. *Visiting scholar from the Institute of Pharmacology and Tnxirology, Bci-
jing. People's Republic of China.

Address reprint requests to Steven R. Kass, Department of Chemistry, University of Minnesota, Minneapolis, MN 55455.
We report herein our experimental studies, carried out with a variable temperature flowing afterglow apparatus, on the formation, reactivity, and thermodynamic properties of 1 .

\section{Experimental}

Among the various techniques for examining gas phase ion-molecule reactions, the flowing afterglow device has proved to be especially valuable. A number of reviews of this method have appeared in the literature, including a recent and comprehensive one by Graul and Squires [5]. Our apparatus was modeled after the Boulder selected ion flow tube [6] and is illustrated schematically in Figure 1. It consists of three separate regions: ion source, reaction tube, and detector, and can currently be operated over a temperature range of $\sim-193^{\circ}$ to $400{ }^{\circ} \mathrm{C}$.

Ions are produced by passing a small amount of an appropriate precursor by a thoria-coated iridium filament (Electron Technology Co.) biased at -20 to $-30 \mathrm{~V}$ relative to a grounded accelerating grid and operated in a constant emission current mode $(\sim 0.025 \mathrm{~mA}$ to $0.5 \mathrm{~mA})$. The resulting ions are carried down a $106-\mathrm{cm}$ long $\times 7.3-\mathrm{cm}$ i.d. flow tube by a constant flow (100-250 STP $\mathrm{cm}^{3} \mathrm{~s}^{1}$ ) of a fast-moving $\left(v \approx 9000 \mathrm{~cm} \mathrm{~s}^{-1}\right)$ inert buffer gas, typically helium. System pressures of 27 to $173 \mathrm{~Pa}$ are measured with an MKS Baratron capacitance manometer and are maintained with a Kinney model MB1600/TOC150 booster pumping system (547 $\mathrm{L} \mathrm{s}^{-1}$ for air at $53 \mathrm{~Pa}$ ). Under these conditions the ions undergo rapid collisional relaxation, and thermal equilibration with the walls of the instrument is established. In situ multistep syntheses are conveniently carried out by adding neutral reagents at successive points along the flow tube, and converting ions from one to another. Likewise, the measurement of rate constants is extremely facile because distance is linearly related to time. As a result, rate constants can be obtained by introducing a constant flow of a neu- 


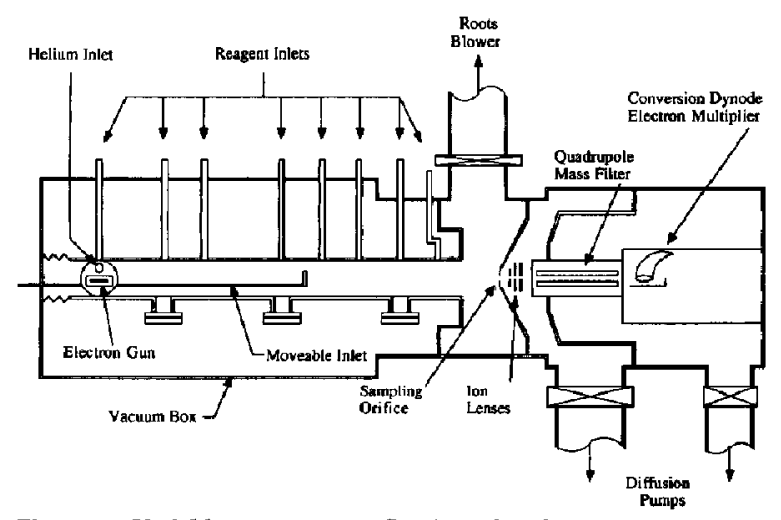

Figure 1. Variable temperature flowing afterglow apparatus.

tral reagent at several points along the flow tube and monitoring the ion intensity. A movable inlet along with sixteen fixed inlets at eight different locations are available. The bulk of the material passing down the flow tube is exhausted by the pumping system, but a small fraction of the ions is sampled through a 0.5$\mathrm{mm}$ molybdenum orifice located at the blunted end of a $120^{\circ}$ stainless steel nose cone. The detection region is differentially pumped with two Varian oil diffusion pumps, an M6 and an M4, and is maintained at a pressure between $10^{-4}$ and $10^{-5} \mathrm{~Pa}$. The ions are focused with a three-element Einzel Co., lens, separated with a flange-mounted 5/8" Extrel quadrupole mass filter (1-450 u, Model 7-270-9), and detected with a conversion dynode electron multiplier. The resulting pulses are fed into a Modern Instrumentation Technology preamplifier-discriminator ( $20 \mathrm{~ns}$ pulse-pair resolution, Model F-100T), and are counted either with the same company's PRM-100 ratemeter or a Teknivent Co. data system interfaced to a Zenith $248 \mathrm{PC}$. In this way real-time mass spectra can be obtained manually or under computer control.

The temperature of the system can be varied by heating or cooling the helium buffer gas, the neutral reagents (if desired), and the entire flow tube. This is accomplished by thermally isolating the ion source and reaction region with a vacuum box, and using heaters and cooling coils. The pressure in the box is typically maintained at $\sim 10^{-3} \mathrm{~Pa}$ with a $2^{\prime \prime}$ diffusion pump backed with a 2020A Alcatel mechanical pump (7.1 $\mathrm{L} \mathrm{s}^{-1}$ ). An Omega CN5001 temperature controller is used to maintain a constant temperature, and four type J thermocouples are used as monitors. Subambient temperatures are achieved with liquid nitrogen or a Neslab Co. Cryocool CC-100 refrigeration system rated to $100^{\circ} \mathrm{C}$. Resistive tubular heaters with a maximum sheath temperature of $870^{\circ} \mathrm{C}$ (Chromalox TRI-5212) are used for elevated temperatures. Overall, the currently accessible temperature range is $\sim-193^{\circ}$ to 400 ${ }^{\circ} \mathrm{C}$.

In these experiments electron impact on $\mathrm{NF}_{3}$ or perfluoropropylene afforded large signals of $\mathrm{F}^{-}(m / z 19)$. Trimethylsilylmethanethiol was prepared and purified as described by Block et al. [7]. The deuterated reagent (SD) was obtained by hydrogen-deuterium exchange with deuterium oxide. All of the other materials used in this investigation were obtained from commercial suppliers. Liquid samples were subjected to several freeze-pump-thaw cycles to remove any noncondensible impurities, and gaseous materials were used as supplied. Gas purities (minimum) and sources were as follows: He (Air Products, 99.995\%), $\mathrm{NF}_{3}$ (Air Products, $99.0 \%$ ), perfluoropropylene (Matheson, 99.5\%), $\mathrm{CO}_{2}$ (Matheson, 99.8\%), $\mathrm{COS}$ (Matheson, 97.5\%), $\left(\mathrm{CH}_{3}\right)_{2} \mathrm{NH}$ (Scott, $99.0 \%$ ), $\mathrm{N}_{2} \mathrm{O}$ (Air Products, $99.99 \%$ ), $\mathrm{O}_{2}$ (Matheson, 99.6\%), and $\mathrm{SO}_{2}$ (Linde, $99.9 \%$ ).

\section{Results and Discussion}

Trimethylsilylmethanethiol (2) reacts with $\mathrm{F}^{-}$in our flowing afterglow apparatus at low conversions to afford three product ions in a $\sim 75: 20: 5$ ratio (eq 2). Proton transfer is the major pathway (ion 3 has previously

$$
\begin{aligned}
& \left(\mathrm{CH}_{3}\right)_{3} \mathrm{SiCH}_{2} \mathrm{SH} \stackrel{\mathrm{F}^{-}}{\longrightarrow}\left(\mathrm{CH}_{3}\right)_{3} \mathrm{SiCH}_{2} \mathrm{~S}^{-}+{ }^{-} \mathrm{CH}_{2} \mathrm{SH}+\mathrm{CH}_{3} \mathrm{~S}^{-} \\
& \begin{array}{ccccc}
m / 2 & 119 & & 47 & 47 \\
\text { yield } & -75 & : & 20 & : \\
& 3 & & 1 & 4
\end{array}
\end{aligned}
$$

been prepared [8]), a significant fraction proceeds via attack at the silicon center leading to fluorodesilylation and the formation of the thiomethyl anion (1), and a minor amount of methylthiolate (4) is also produced. The latter two species are isomeric but can readily be distinguished because 1 is much more reactive than 4 . For example, $\mathrm{D}_{2} \mathrm{O}, \mathrm{N}_{2} \mathrm{O}$, and $\mathrm{O}_{2}$ all react rapidly with the thiomethyl anion but are inert to the thiolate ion. The relative amount of the two isomers was therefore determined by difference-that is, the initial signal at $m / z 47$ due to both ions was compared to the intensity at the same mass after reacting away 1 , using all three reagents.

The products of the reaction of the thiomethyl anion with $\mathrm{D}_{2} \mathrm{O}\left(\Delta H_{\text {acid }}=1640 \mathrm{~kJ} \mathrm{~mol}^{-1}\right)$ [9] are $\mathrm{OD}^{-}$and an $m / z 48$ ion. The formation of both of these anions is illustrated in Scheme I and is reminiscent of the behavior of the acetyl anion $\left(\mathrm{CH}_{3} \mathrm{CO}^{-}\right)$[1c]. Less acidic reagents such as $\left(\mathrm{CH}_{3}\right)_{2} \mathrm{NH}$ and $\mathrm{NH}_{3}, \Delta H_{\text {acid }}=1658$ and $1689 \mathrm{~kJ} \mathrm{~mol}^{-1}$, respectively [9], catalyze the isomerization of 1 to 4 , but do not appear to be strong enough to protonate it since their conjugate bases are not observed. Therefore, we conclude that the proton affinity of 1 is between the values for $\mathrm{OD}^{-}$ and $\left(\mathrm{CH}_{3}\right)_{2} \mathrm{~N}^{-}$and assign it a value of $1649 \pm 12 \mathrm{~kJ}$ $\mathrm{mol}^{-1}$. This result is in reasonable accord with Downard et al.'s [4] ab initio molecular orbital value of $1669 \mathrm{~kJ} \mathrm{~mol}^{-1}$ obtained at the MP4/6-311++ $+\mathrm{G}^{* *} / / 6-$ $311++G^{* *}$ level.

Several pathways can account for the formation of methylthiolate ion in the reaction of $\mathrm{F}^{-}$with 2 . A particularly appealing one, in accord with the data presented above, is the isomerization of 1 to 4 brought about by trimethylsilylmethanethiol. Consistent with this explanation is our observation that when the reac- 


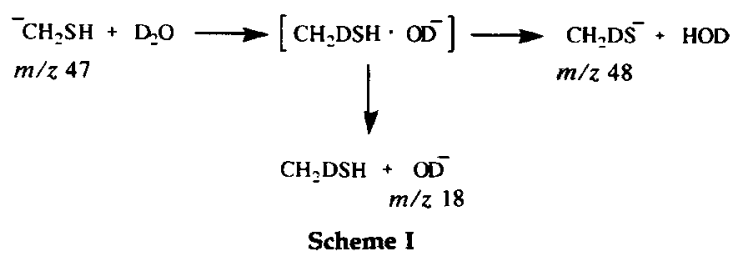

tion is run to higher conversions the $1: 4$ ratio, and the total amount of these two ions, decreases. This scheme can account for all of the thiolate ion, but we cannot entirely rule out a contribution from a direct pathway (Scheme II). On the basis of previous results [1c, 10], the absence of an $m / z 91$ ion, and the tendency for carbon acids to undergo slow proton transfers [11], it seems unlikely that the process in Scheme II is occurring to any significant extent.

An alternative explanation for the formation of 4 that needs to be considered is a unimolecular rearrangement. The driving force for such a reaction is $\mathbf{1 5 6}$ $\mathrm{kJ} \mathrm{mol}^{-1}$. Despite this unusually large thermodynamic impetus, the thiomethyl anion does not isomerize at thermal energies in the millisecond time frame of our experiment (eq 3). In an attempt to induce the proton shift, we generated 1 at several temperatures between

${ }^{-} \mathrm{CH}_{2} \mathrm{SH} \underset{-40^{\circ}-100^{\circ}}{\stackrel{\mathrm{C}}{\longrightarrow}} \mathrm{CH}_{3} \mathrm{~S}^{-} \Delta H=-156 \mathrm{~kJ} \mathrm{~mol}^{-1}$

$\sim-40^{\circ}$ and $100^{\circ} \mathrm{C}$, but this had no effect on the $1: 4$ ratio. A dramatic change would have been expected if a unimolecular rearrangement was occurring. Clearly there is a significant activation energy for this process in accord with the Woodward-Hoffmann rules [2].

The electron affinity (EA) of the thiomethyl radical, . $\mathrm{CH}_{2} \mathrm{SH}$, is related to the carbon-hydrogen bond dissociation energy (BDE) of methanethiol $\left(\mathrm{CH}_{3} \mathrm{SH}, 5\right)$, the ionization potential (IP) of atomic hydrogen, and the proton affinity (PA) of the thiomethyl anion by the thermodynamic cycle shown in eqs 4-7. We have measured $\mathrm{PA}(1)$, and both the $\operatorname{IP}(\mathrm{H} \cdot)$ and the

$$
\begin{gathered}
\mathrm{CH}_{3} \mathrm{SH} \rightarrow \mathrm{CH}_{2} \mathrm{SH}+\mathrm{H} \cdot \mathrm{BDE}\left(\mathrm{H}-\mathrm{CH}_{2} \mathrm{SH}\right) \\
\mathrm{H} \cdot \leftarrow \mathrm{H}^{+}+e^{-} \mathrm{P}(\mathrm{H} \cdot) \\
-\mathrm{CH}_{2} \mathrm{SH}+\mathrm{H}^{+} \leftarrow \mathrm{CH}_{3} \mathrm{SH}-\mathrm{PA}\left(-\mathrm{CH}_{2} \mathrm{SH}\right)
\end{gathered}
$$

$$
-\mathrm{CH}_{2} \mathrm{SH} \rightarrow \cdot \mathrm{CH}_{2} \mathrm{SH}+e^{-} \mathrm{EA}\left(\cdot \mathrm{CH}_{2} \mathrm{SH}\right)
$$

$\mathrm{EA}\left(\cdot \mathrm{CH}_{2} \mathrm{SH}\right)$

$$
=\mathrm{BDE}\left(\mathrm{H}-\mathrm{CH}_{2} \mathrm{SH}\right)+\mathrm{IP}(\mathrm{H} \cdot)-\mathrm{PA}\left({ }^{-} \mathrm{CH}_{2} \mathrm{SH}\right)
$$

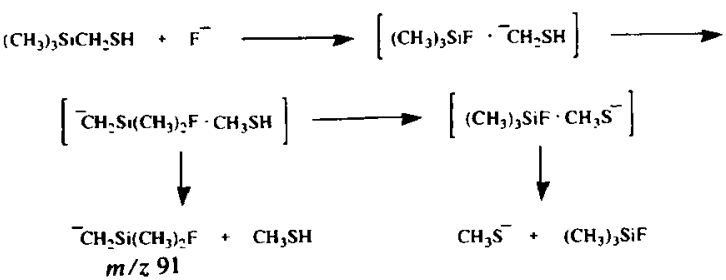

Scheme II

$\mathrm{C}-\mathrm{H}$ BDE of 5,1312 and $402 \pm 4 \mathrm{~kJ} \mathrm{~mol}^{-1}$, respectively, have been reported $[9,12]$. Substitution into eq. 8 leads to an electron affinity for the thiomethyl radical of $65 \pm 13 \mathrm{~kJ} \mathrm{~mol}^{-1}(0.67 \pm .13 \mathrm{eV})$, which is in accord with our observation that 1 undergoes electron transfer to $\mathrm{SO}_{2}(\mathrm{EA}=1.11 \mathrm{eV})[9]$ and does not appear to do so with $\mathrm{O}_{2}(\mathrm{EA}=0.451 \mathrm{eV})$ [13]. Many additional compounds with electron affinities between those for oxygen and sulfur dioxide are known and could be used to refine the bracketed value [14]. However, it has been our experience that many of these reagents are not very volatile and almost all of them contain acidic hydrogens. As a result, basic ions such as 1 often undergo uninformative proton transfer reactions. This is exactly what happens with biacetyl $\left(\mathrm{CH}_{3} \mathrm{COCOCH}_{3}, \mathrm{EA}=0.69 \mathrm{eV}\right)$ [9]; 1 readily deprotonates it and no electron transfer is observed. Consequently, nothing can reliably be concluded about the electron affinities in this instance. In addition, bracketing experiments are unlikely to provide a more precise EA than was obtained from the thermodynamic cycle (eqs 4-7); therefore, further experiments were not carried out. These results do provide excellent support for the contention made by Grabowski et al. [15] that the observed electron transfer between $\mathrm{CH}_{3} \mathrm{~S}^{-}$and $\mathrm{SO}_{2}$ in an ion cyclotron resonance spectrometer was due to thiomethyl anion contamination. On the other hand, a recent molecular orbital calculation predicted an electron affinity for 1 of $0.243 \mathrm{eV}$ [4]. We believe that this value is too small and that given the difficulty in accurately computing electron affinities, this discrepancy is not surprising.

The reactivity of the thiomethyl anion was examined with a variety of reagents including $\mathrm{N}_{2} \mathrm{O}, \mathrm{O}_{2}$, $\mathrm{CS}_{2}, \mathrm{COS}, \mathrm{CO}_{2}$, and $\mathrm{SO}_{2}$. The results of these reactions along with some thermodynamic data are summarized in Table 1 . Heats of formation used in this study are given in Table 2 . In every case hydride ion transfer is observed, which is consistent with the small hydride ion binding energy of 1 (eq 9). Nitrous oxide,

${ }^{-} \mathrm{CH}_{2} \mathrm{SH} \longrightarrow \mathrm{CH}_{2}=\mathrm{S}+\mathrm{H}^{-} \Delta H^{\circ}=154 \mathrm{~kJ} \mathrm{~mol}^{-1}$

for example, reacts readily with the thiomethyl anion to afford $\mathrm{HN}_{2} \mathrm{O}^{-}(m / z 45)$ as the major product (eq 10). Smaller amounts of $\mathrm{OH}^{-}$and $\mathrm{SH}^{-}(m / z) 17$

$$
-\mathrm{CH}_{2} \mathrm{SH}+\mathrm{N}_{2} \mathrm{O} \longrightarrow \mathrm{HN}_{2} \mathrm{O}^{-}+\mathrm{OH}^{-}+\mathrm{SH}^{-}
$$


Table 1. Products, relative amounts, and thermochemistry derived from the reactions of the thiomethyl anion $(\mathbf{1})^{a}$

\begin{tabular}{|c|c|c|c|}
\hline Reagent & Products & Relative amounts ${ }^{b}$ & $\begin{array}{l}\text { Thermochemistry } \\
\left(\mathrm{kJ} \mathrm{mol}^{-1}\right)\end{array}$ \\
\hline$\overline{\mathrm{N}_{2} \mathrm{O}}$ & $\begin{array}{l}\mathrm{HN}_{2} \mathrm{O}^{-}+\mathrm{CH}_{2} \mathrm{~S} \\
\mathrm{OH}^{-}+\mathrm{CH}_{2} \mathrm{~S}+\mathrm{N}_{2} \\
\mathrm{SH}^{-}+\left(\mathrm{CH}_{2} \mathrm{~N}_{2} \mathrm{O}\right)\end{array}$ & $\begin{array}{r}-70 \% \\
20 \% \\
10 \%\end{array}$ & $\begin{array}{l}\Delta \mathrm{H}^{\circ}{ }_{\mathrm{f}}\left(\mathrm{HN}_{2} \mathrm{O}^{-}\right) \leq 73 \\
\Delta \mathrm{H}^{\circ}=-210\end{array}$ \\
\hline $\mathrm{O}_{2}$ & $\begin{array}{l}\mathrm{HCOS}^{-}+\mathrm{H}_{2} \mathrm{O} \\
\mathrm{HO}_{2}^{-}+\mathrm{CH}_{2} \mathrm{~S}\end{array}$ & $\begin{array}{r}-66 \% \\
33 \%\end{array}$ & $\begin{array}{l}\Delta H^{\circ}=-613 \\
\Delta H^{\circ}=-85\end{array}$ \\
\hline $\mathrm{Cs}_{2}$ & $\begin{array}{l}\mathrm{HCS}_{2}^{-}+\mathrm{CH}_{2} \mathrm{~S} \\
\mathrm{SH}^{-}+\left(\mathrm{C}_{2} \mathrm{H}_{2} \mathrm{~S}_{2}\right) \\
-\mathrm{S}-\mathrm{CH}=\mathrm{C}=\mathrm{S}+\mathrm{H}_{2} \mathrm{~S}\end{array}$ & $\begin{array}{r}-95 \% \\
5 \% \\
\text { trace }\end{array}$ & $\begin{array}{l}\Delta H^{\circ}=-127 \\
\Delta H_{f}^{\circ}\left({ }^{-} S-C H=C=S\right) \leq 234\end{array}$ \\
\hline $\cos$ & $\begin{array}{l}\mathrm{SH}^{-}+\mathrm{CH}_{2} \mathrm{~S}+\mathrm{CO} \\
-\mathrm{S}-\mathrm{CH}=\mathrm{C}=\mathrm{O}+\mathrm{H}_{2} \mathrm{~S} \\
\mathrm{HCOS}+\mathrm{CH}_{2} \mathrm{~S}\end{array}$ & $\begin{array}{r}-85 \% \\
10 \% \\
5 \%\end{array}$ & $\begin{array}{l}\Delta H^{\circ}=-41 \\
\Delta H^{\circ}{ }_{f}(-S-C H=C=0) \leq-25 \\
\Delta H^{\circ}=-124\end{array}$ \\
\hline $\mathrm{CO}_{2}$ & $\begin{array}{l}\mathrm{HSCH}_{2} \mathrm{CO}_{2}^{-} \\
\mathrm{HCO}_{2}^{-}+\mathrm{CH}_{2} \mathrm{~S}\end{array}$ & $\begin{array}{r}-85 \% \\
15 \%\end{array}$ & $\Delta H^{\circ}=-61$ \\
\hline $\mathrm{SO}_{2}$ & $\begin{array}{l}\mathrm{SO}_{2}^{-}+\mathrm{CH}_{2} \mathrm{SH} \\
\mathrm{HSO}_{2}^{-}+\mathrm{CH}_{2} \mathrm{~S} \\
\mathrm{HSCH}_{2} \mathrm{SO}_{2}^{-}\end{array}$ & $\begin{array}{r}-70 \% \\
20 \% \\
10 \%\end{array}$ & $\begin{array}{l}\mathrm{EA}\left(\mathrm{CH}_{2} \mathrm{SH}\right) \leq 1.11 \mathrm{eV} \\
\Delta H^{\circ}=-109\end{array}$ \\
\hline
\end{tabular}

\footnotetext{
a The neutral products from these reactions are inferred on the basis of reasonable mechanisms that have previously been put forth in the literature; they are not observed in these experiments.

${ }^{b}$ The relative amounts of the product ions were not obtained by extrapolating to zero flow of the neutral reagent and therefore are only a guide to the behavior of these reactions.
}

Table 2. Heats of formation (in $\mathrm{kJ} \mathrm{mol}^{-1}$ )

\begin{tabular}{lcclcc}
\hline Species & $\Delta \mathrm{H}_{f}{ }^{\circ}$ & Reference & \multicolumn{1}{c}{ Species } & \multicolumn{1}{c}{$\mathrm{H}_{\mathrm{f}}{ }^{\circ}$} & Reference \\
\hline \hline $\mathrm{CH}_{2} \mathrm{SH}$ & 96 & This work & $\mathrm{CS}_{2}$ & 117 & {$[9]$} \\
$\mathrm{CH}_{3} \mathrm{SH}$ & -23 & {$[9]$} & $\mathrm{HCS}_{2}^{-}$ & -19 & {$[17]$} \\
$\mathrm{H}^{+}$ & 1530 & {$[9]$} & $\mathrm{SH}^{-}$ & -81 & {$[9]$} \\
$\mathrm{CH}_{3} \mathrm{~S}^{-}$ & -60 & {$[9]$} & $\mathrm{H}_{2} \mathrm{~S}$ & -21 & {$[9]$} \\
$\mathrm{H}^{-}$ & 145 & {$[9]$} & $-\mathrm{S}-\mathrm{CH}=\mathrm{C}=\mathrm{S}$ & $\leq 234$ & This work \\
$\mathrm{CH}_{2} \mathrm{~S}$ & 105 & {$[9]$} & $\mathrm{CO}$ & -110.53 & {$[9]$} \\
$\mathrm{HN}_{2} \mathrm{O}^{-}$ & $\leq 73$ & This work & $-\mathrm{S}-\mathrm{CH}=\mathrm{C}=\mathrm{O}$ & $\leq-25$ & This work \\
& & (lit. $\leq 130[17])$ & & & \\
$\mathrm{N}_{2} \mathrm{O}$ & 82.1 & {$[9]$} & $\mathrm{COS}$ & -142 & {$[9]$} \\
$\mathrm{OH}^{-}$ & -137 & {$[9]$} & $\mathrm{HCOS}-$ & -275 & {$[17]$} \\
$\mathrm{H}_{2} \mathrm{O}_{2}$ & -136.3 & {$[9]$} & $\mathrm{CO}$ & -393.51 & {$[9]$} \\
$\mathrm{CH}_{3} \mathrm{O}^{-}$ & -139 & {$[9]$} & $\mathrm{HCO}_{2}^{-}$ & -464 & {$[9]$} \\
$\mathrm{CH}_{2} \mathrm{O}$ & -108.7 & {$[9]$} & $\mathrm{SO}_{2}$ & -296.8 & {$[9]$} \\
$\mathrm{H}_{2} \mathrm{O}$ & -242 & {$[9]$} & $\mathrm{HSO}_{2}^{-}$ & -415 & {$[9]$} \\
$\mathrm{HO}_{2}^{-}$ & -94 & {$[9]$} & $\mathrm{CS}^{-}$ & 268 & {$[9]$} \\
\hline
\end{tabular}

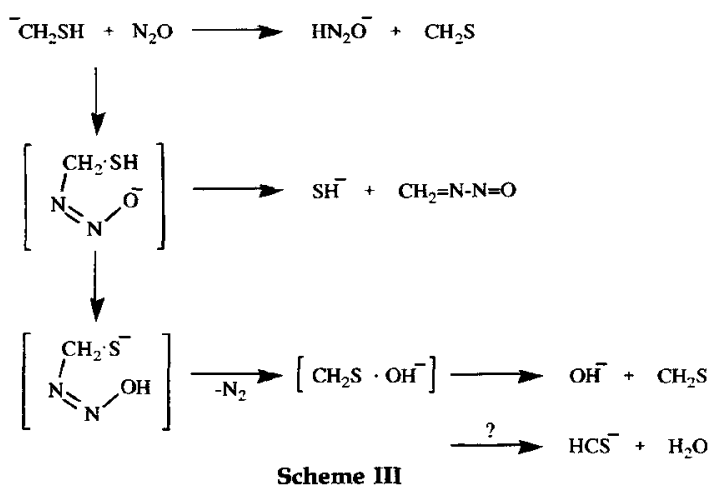

and 33, respectively) are also produced and can be accounted for by the mechanism illustrated in Scheme III. (It is worth noting that although there are no examples of thermal proton rearrangements, many isomerizations of energetically excited adducts have been reported [16].) Consistent with this proposal is our observation that the reaction of $-\mathrm{CH}_{2} \mathrm{SD}$, generated from deuterium-labeled trimethylsilylmethanethiol, yields $\mathrm{DN}_{2} \mathrm{O}^{-}, \mathrm{OD}^{-}$, and $\mathrm{SD}^{-}(m / z 46,18$, and 34 , respectively). The formation of the thioformyl anion, $\mathrm{HCS}^{-}(m / z 45)$, which has the same nominal mass as $\mathrm{HN}_{2} \mathrm{O}^{-}$, is inconsistent with the labeling study. However, the deuterium-labeled thiomethyl anion was not isotopically pure $(\sim 75 \% \mathrm{D})$ and consequently some 
$m / z 45$ was produced. As a result, we cannot entirely rule out the formation of minor amounts $(\leq 10 \%)$ of $\mathrm{HCS}^{-}$. Thermodynamic information derived from this reaction is given in Table 1 . In particular, an upper bound for the heat of formation of $\mathrm{HN}_{2} \mathrm{O}^{-}$can be deduced if we assume that it is formed in an exothermic process. This seems reasonable since the reaction between 1 and $\mathrm{N}_{2} \mathrm{O}$ is quite rapid. Our value, $\Delta H_{f}^{\circ}\left(\mathrm{HN}_{2} \mathrm{O}^{-}\right) \leq 73 \mathrm{~kJ} \mathrm{~mol}^{-1}$, is in accord with a previous determination of $\Delta H_{f}^{\circ}\left(\mathrm{HN}_{2} \mathrm{O}^{-}\right) \leq 130 \mathrm{~kJ} \mathrm{~mol}^{-1}$ [17]. In contrast to 1 , methoxide does not react with $\mathrm{N}_{2} \mathrm{O}$ [8] even though it binds hydride to only a slightly greater extent (eq 11). This lack of reactivity may reflect a kinetic barrier, or it may indicate that hydride

$\mathrm{CH}_{3} \mathrm{O}^{-} \longrightarrow \mathrm{CH}_{2}=\mathrm{O}+\mathrm{H}^{-} \Delta H^{\circ}=175 \mathrm{~kJ} \mathrm{~mol}^{-1}$

transfer is endothermic. If the latter explanation is correct, then a lower limit of $52 \mathrm{~kJ} \mathrm{~mol}^{-1}$ can be placed on the heat of formation of $\mathrm{HN}_{2} \mathrm{O}^{-}$.

Oxygen reacts readily with 1 to form two product ions, $\mathrm{HCOS}^{-}$and $\mathrm{HO}_{2}^{-}$( $m / z 61$ and 33, respectively), in approximately a $2: 1$ ratio. The hydroperoxy anion is the result of an exothermic hydride ion transfer, $\Delta H^{\circ}=-85 \mathrm{~kJ} \mathrm{~mol}^{-1}$, while the thioformate anion presumably arises from addition followed by proton transfer and dehydration (eq 12). The latter pathway is driven by an unusually large reaction exothermicity of

$$
\begin{aligned}
-\mathrm{CH}_{2} \mathrm{SH} & +\mathrm{O}_{2} \longrightarrow \mathrm{O}_{2} \mathrm{H}^{-}+\mathrm{CH}_{2} \mathrm{~S} \\
& \longrightarrow\left[\mathrm{HSCH}_{2}-\mathrm{O}_{-} \mathrm{O}^{-}\right] \longrightarrow\left[\begin{array}{r}
-\mathrm{S}-\mathrm{CH}-\mathrm{O} \\
\mathrm{r} \\
\mathrm{H} \mathrm{OH}
\end{array}\right] \stackrel{\stackrel{\mathrm{O}}{1}}{\longrightarrow}-\mathrm{H}_{2} \mathrm{O}-\mathrm{H}-\mathrm{C}-\mathrm{S}-
\end{aligned}
$$

$613 \mathrm{~kJ} \mathrm{~mol}^{-1}$. Both channels require a change in multiplicity because molecular oxygen is a ground-state triplet, but this obstacle can readily be overcome, as previously explained [18], by an initial electron transfer step.

Carbon disulfide, carbonyl sulfide, and carbon dioxide all react with 1 via hydride ion transfer, but the product ion distributions differ markedly. In particular, $\mathrm{CS}_{2}$ is reduced to afford $\mathrm{HCS}_{2}^{-}$almost exclusively, $\mathrm{COS}$ reacts to give $\mathrm{SH}^{-}$as the dominant product ion, and $\mathrm{CO}_{2}$ leads mainly to an adduct. The products all can be accounted for by a variety of pathways including: hydride ion transfer to carbon or sulfur, addition, addition followed by fragmentation, $\mathrm{SH}^{-}$elimination, and sulfur atom transfer, all of which have previously been described [19]. The difference in behavior between $\mathrm{CS}_{2}$ and $\mathrm{COS}$, however, is worth commenting on. Both compounds have very similar hydride ion affinities ( 281 and $278 \mathrm{~kJ} \mathrm{~mol}^{-1}$ ), yet COS reacts to give only a small amount of $\mathrm{HCOS}^{-}$. The major product, $\mathrm{SH}^{-}$, can be accounted for by sulfur atom transfer followed by elimination of thioformaldehyde. This product most likely results from the greater tendency for COS to lose $\mathrm{CO}\left(\Delta H_{f}^{\circ}(\mathrm{CO})-\Delta H_{f}^{\circ}(\mathrm{COS})=\right.$ $\left.31.5 \mathrm{~kJ} \mathrm{~mol}^{-1}\right)$ than for $\mathrm{CS}_{2}$ to lose CS $\left(\Delta H_{f}^{\circ}(\mathrm{CS})-\right.$ $\left.\Delta H_{f}^{\circ}\left(\mathrm{CS}_{2}\right)=151 \mathrm{~kJ} \mathrm{~mol}^{-1}\right)$. In accord with this notion, we and others have observed that COS often undergoes sulfur atom transfer under conditions in which $\mathrm{CS}_{2}$ does not $[8,20]$.

In summary, we have shown that the thiomethyl anion can be prepared by fluorodesilylation of trimethylsilylmethanethiol in our variable temperature flowing afterglow apparatus. The anion has a proton affinity of $1649 \pm 12 \mathrm{~kJ} \mathrm{~mol}^{-1}$, has an electron affinity of $0.67 \pm .13 \mathrm{eV}$, and is a potent hydride ion donor. It does not rearrange at temperatures up to $100{ }^{\circ} \mathrm{C}$ despite a $156 \mathrm{~kJ} \mathrm{~mol}^{-1}$ driving force for a 1,2-proton shift. This is the result of a significant activation energy barrier, and is in accord with Woodward-Hoffmann rules [2]. Heats of formation for $-\mathrm{CH}_{2} \mathrm{SH}, \mathrm{HN}_{2} \mathrm{O}^{-}$, $-\mathrm{S}-\mathrm{CH}=\mathrm{C}=\mathrm{S}$, and $-\mathrm{S}-\mathrm{CH}=\mathrm{C}=\mathrm{O}$ have been established, and the reactivity of 1 with a number of reagents has been explored.

\section{Acknowledgments}

Acknowledgment is made to the donors of the Petroleum Research Fund, administered by the American Chemical Society, for partial support of this research. Support from the National Science Foundation under grant no. CHE-8907198 and the University of Minnesota McKnight-Land Grant Professorship is gratefully acknowledged. We owe a particular debt to Charles DePuy, Veronica Bierbaum, Steven Barlow, Jane Van Doren, Barney Ellison, David Smith, Nigel Adams, Harley Steinbrenner, and Bruce Moe for their assistance in designing and building the flowing afterglow apparatus used in this investigation. In addition, we thank the referees for several helpful suggestions.

\section{References}

1. (a) Damrauer, R.; Kass, S. R.; DePuy, C. H. Organometallics 1988, 7, 637-640/(b) Klass, G.; Trenerry, V. C.; Shelton, J. C.; Bowie, J. H. Aust. J. Chem. 1981, 34, 519-529/(c) DePuy, C. H.; Bierbaum, V. M.; Damrauer, R.; Soderquist, J. A. J. Am. Chem. Soc. 1985, 107, 3385. (d) Anderson, K. K.; Kass, S. R. Tet. Letts. 1989, 30, 3045-3048. (e) Graul, S. T.; Squires, R. R. J. Am. Chem. Soc. 1988, 110, 607-608. (f) Froelicher, S. W.; Freiser, B. S.; Squires, R. R. J. Am. Chem. Soc. 1986, 108, 2853-2862.

2. Woodward, R. B.; Hoffmann, R. The Conseration of Orbital Symmetry; Academic: Germany, 1971.

3. (a) Wetzel, D. M.; Salomon, K. E.; Berger, S.; Brauman, J. I. J. Am. Chem. Soc. 1989, 111, 3835-3841. (b) Bartmess, J. E.; Hays, R. L.; Khatri, H. N.; Misra, R. N.; Wilson, S. J. Am. Chem. Soc. 1981, 103, 4746-4751. (c) Ingemann, S.; Nibbering, N. M. M. Can. J. Chem. 1984, 62, 2273-2281. (d) Ingemann, S.; Nibbering, N. M. M. J. Chem. Soc. Perkin Trans. II, 1985, 837-840. (e) Grabowski, J. J.; Roy, P. D.; Leone, R. J. Chem. Soc. Perkin Trans. II, 1988, 1627-1632.

4. Downard, K. M.; Sheldon, J. C.; Bowie, J. H.; Lewis, D. E.; Hayes, R. N. J. Am. Chem. Soc. 1989, 111, 8112-8115.

5. Graul, S. T.; Squires, R. R. Mass. Spectrom. Reus. 1988, 7, 263-358.

6. Grabowski, J. J.; DePuy, C. H.; Bierbaum, V. M. J. Am. Chem. Soc. 1983, 105, 2565-2571.

7. Block, E.; Laffitte, J. A.; Eswarakrishnan, V. J. Org. Chem. 1986, 51, 3428-3435.

8. Bierbaum, V. M.; Grabowski, J. J.; DePuy, C. H. J. Phys. Chem. 1984, 88, 1389-1393. 
9. Lias, S. G.; Bartmess, J. E.; Holmes, J. L.; Levin, R. D.; Liebman, J. F.; Mallard, W. G. J. Phys. Chem. Ref. Data 1988, 17, Suppl. 1.

10. Depuy, C. H.; Bierbaum, V. M.; Flippin, L. A.; Grabowski, J. J.; King, G. K.; Schmitt, R. J.; Sullivan, S. A. J. Am. Chem. Soc. 1980, 102, 5012-5015.

11. (a) Farneth, W. E.; Brauman, J. 1. J. Am. Chem. Soc. 1976, 98 , 7891-7898. (b) Moylan, C. R.; Brauman, J. I. Ann. Rev. Phys. Chem. 1983, 34, 187-215.

12. Shum, L. G. S.; Benson, S. W. Int. J. Chem. Kinetics 1983, 15, 433-453.

13. Travers, M.; Cowles, D.; Ellison, G. B. personal communication.

14. Kebarle, P.; Chowdhury, S. Chem. Rev. 1987, 87, 513-534.
15. Grabowski, J. J.; Van Doren, J. M.; DePuy, C. H.; Bierbaum, V. M. J. Chem. Phys. 1984, 80, 575-577.

16. (a) DePuy, C. H. In Ionic Processes in the Gas Phase; Ferreira, M. A. A., Ed.; D. Reidel Publishing: New York, 1984; pp. 227-241.(b) Kass, S. R.; Filley, J.; Van Doren, J. M.; DePuy, C. H. 1. Am. Chem. Soc. 1986, 108, 2849-2852.

17. Kass, S. R.; DePuy, C. H. J. Org. Chem. 1985, 50, 2874-2877.

18. (a) Schmitt, R. J.; Bierbaum, V. M.; DePuy, C. H. J. Am. Chem. Soc. 1979, 101, 6443-6445. (b) Bierbaum, V. M.; Schmitt, R. J.; DePuy, C. H. Environmental Health Perspectives 1980, 36, 119-124.

19. DePuy, C. H. Org. Mass Spectrom. 1985, 20, 556-559.

20. DePuy, C. H.; Bierbaum, V. M. Tet. Letts. 1981, 22, 5129-5130. 